\title{
RESPOSTA DO ARROZ IRRIGADO AO USO DE INIBIDOR DE UREASE EM PLANTIO DIRETO E CONVENCIONAL
}

\author{
Response of rice to the use of urease inhibitor in no-tillage and conventional \\ Mara Grohs¹, Enio Marchesan², Dâmaris Sulzbach Santos², Paulo Fabrício Sachet Massoni², \\ Gerson Meneghetti Sarzi Sartori², Rafael Bruck Ferreira ${ }^{2}$
}

\begin{abstract}
RESUMO
O objetivo do presente trabalho foi avaliar a volatilização de $\mathrm{N}-\mathrm{NH}_{3}$ e a resposta do arroz irrigado ao uso de ureia com inibidor de urease em dois sistemas de cultivo, direto e convencional. Para tanto, desenvolveu-se um experimento em campo, no ano agrícola 2008/09, na UFSM em Santa Maria/RS. O delineamento utilizado foi de blocos ao acaso em esquema bifatorial (2x5), sendo o fator A constituído por ureia e ureia revestida com B e Cu (inibidor de urease) e o fator $\mathrm{B}$ composto por diferentes intervalos de entrada de água $(0,3,6,9,12$ dias) após a aplicação das fontes de nitrogênio $(\mathrm{N})$. Os resultados demonstram que o inibidor de urease retarda e diminui a conversão de $\mathrm{N}_{\text {para }} \mathrm{NH}_{3}$, reduzindo as perdas por volatilização, comparativamente à ureia sem inibidor. Entre os sistemas, as perdas são potencializadas no sistema plantio direto. $\mathrm{O}$ inibidor de urease não traz benefícios à produtividade em qualquer um dos sistemas de cultivo utilizados e o estresse causado na planta de arroz pelo atraso no início da irrigação é mais prejudicial do que as perdas causadas pela volatilização de $\mathrm{N}^{-\mathrm{NH}_{3}}$.
\end{abstract}

Termos para indexação: Ureia, perdas de nitrogênio, Oryza sativa.

\begin{abstract}
The objective of this work was to measure the $\mathrm{N}_{-} \mathrm{NH}_{3}$ volatilization and the response of irrigated rice to the use of urea with urease inhibitor in two cropping systems, no-tillage and conventional. For this, an experiment in field was performed in the crop year 2008/09, at the UFSM in Santa Maria/RS. A random block in factorial scheme (2x5), with the factor A consisting of two nitrogen $(\mathrm{N})$ sources, urea and urea coated with $\mathrm{B}$ and $\mathrm{Cu}$ (urease inhibitor) and the factor B consisting of different intervals of water intake $(0,3,6,9,12$ days) after the application of $\mathrm{N}$ sources. The results demonstrated that the urease inhibitor slows and decreases the conversion of $\mathrm{N}$ to $\mathrm{NH}_{3}$, reducing the losses by volatilization, comparatively to urea without inhibitor. Between the systems, the losses were increased in the no-tillage system. The urease inhibitor does not add benefits to the productivity in both cropping systems used and the stress caused on the rice plant by the delay of water intake is more harmful than the losses caused by the volatilization of $\mathrm{N}^{-\mathrm{NH}_{3}}$.
\end{abstract}

Index terms: Urea, nitrogen losses, Oryza sativa.

(Recebido em 20 de abril de 2010 e aprovado em 11 de novembro de 2010)

\section{INTRODUÇÃO}

A produtividade das grandes culturas é altamente dependente do elemento nitrogênio (N) uma vez que é constituinte de vários compostos em plantas (Cantarella, 2007). Na cultura do arroz irrigado, recomendase aplicá-lo: na semeadura, no momento do estabelecimento da lâmina de água e na iniciação do primórdio floral, sendo aplicado o maior volume de nitrogênio no momento da irrigação definitiva, aproveitando dessa maneira, para que o elemento seja incorporado ao solo (Mendéz et al., 2001; Scivittaro \& Machado, 2004), evitando perdas significativas pelo processo de volatilização de amônia $\left(\mathrm{NH}_{3}\right)$ (Sociedade Sul-Brasileira de Arroz Irrigado - SOSBAI, 2007). Porém, em muitos casos, dependendo do tamanho da lavoura, o produtor tem dificuldades no estabelecimento da lâmina de água no intervalo recomendado (três dias), tornando o fertilizante suscetível a perdas, diminuindo assim sua eficiência. A ureia, por ser o fertilizante de menor custo por unidade de N, é a fonte mais utilizada na cultura do arroz. Quando aplicada na superfície do solo, sofre hidrólise e a reação é catalisada pela enzima urease presente no solo, perdendo-se para a atmosfera parte do nitrogênio aplicado por volatilização, na forma de gás amônia (Schulten \& Scnitzer, 1998; Duarte et al., 2007). A atividade da urease é estimulada naquelas situações com grandes quantidades de matéria orgânica, como no sistema plantio direto (Vargas et al., 2005) e acaba influenciando significativamente nas perdas por volatilização (Malhi et al., 2001).

\footnotetext{
${ }^{1}$ Universidade Federal de Santa Maria/UFSM - Departamento de Fitotecnia - Avenida Roraima - 1000 - Prédio 44 - Sala 5324 - Camobi - $97105-900$ Santa Maria, RS - maragrohs@yahoo.com.br
}

2Universidade Federal de Santa Maria/UFSM - Departamento de Fitotecnia - Santa Maria, RS 
Uma maneira de aumentar a eficiência dos fertilizantes nitrogenados é o uso de fertilizantes estabilizados, os quais evitam a rápida transformação do $\mathrm{N}$ contido no fertilizante em formas menos estáveis em determinados ambientes (Kiss \& Simihaian, 2002). Esses fertilizantes são conhecidos como inibidores de urease, de nitrificação ou outros aditivos, podendo ser empregado na lavoura de arroz irrigado naqueles casos em que há dificuldades em estabelecer a lâmina de água no intervalo preconizado (Scivittaro et al., 2005).

Do exposto, o presente trabalho foi desenvolvido com o objetivo de avaliar as perdas de $\mathrm{N}$ por volatilização e a resposta do arroz irrigado ao uso de ureia revestida com inibidor de urease $(\mathrm{B}$ e $\mathrm{Cu}$ ) em comparação à ureia convencional, em diferentes intervalos de entrada de água para estabelecimento da lâmina de água após a aplicação do fertilizante, no sistema convencional e plantio direto.

\section{MATERIAL E MÉTODOS}

O experimento foi desenvolvido na safra 2008/09 na Universidade Federal de Santa Maria, Santa Maria, Rio Grande do Sul, em solo classificado como Planossolo Háplico eutrófico arênico pertencente à unidade de mapeamento Vacacaí (Empresa Brasileira de Pesquisa Agropecuária Embrapa, 2006), com as seguintes características: $\mathrm{pH}_{\text {agua }}(1: 1)=5,0 ; \mathrm{P}=11,8 \mathrm{mg} \mathrm{dm}^{-3} ; \mathrm{K}=76 \mathrm{mg} \mathrm{dm}^{-3}$; M.O. $=2,4 \% ; \mathrm{Ca}=4,8 \mathrm{cmol}_{c} \mathrm{dm}^{-3} ; \mathrm{Mg}=1,6 \mathrm{cmol}_{\mathrm{c}} \mathrm{dm}^{-3}$; $\mathrm{Al}=0,5 \mathrm{cmol} \mathrm{dm}^{3} ;$ e argila $=25 \%$. Foram conduzidos dois experimentos alocados lado a lado diferindo apenas no sistema de cultivo (sistema convencional ou sistema plantio direto). Para a obtenção da palhada no sistema plantio direto foi semeado azevém (Lolium multiflorum Lam.), na entressafra, na densidade de $40 \mathrm{~kg} \mathrm{ha}^{-1}$ de semente.

$\mathrm{O}$ delineamento experimental foi de blocos ao acaso em esquema bifatorial $(2 \times 5)$ com quatro repetições. $\mathrm{O}$ fator $\mathrm{A}$ foi composto pelas fontes de nitrogênio $(\mathrm{N})$, sendo ureia (A1) e o inibidor de urease (A2), composto por uréia revestida com boro (B) e cobre $(\mathrm{Cu})(45 \%$ de nitrogênio $(\mathrm{N})$, na forma amídica, 2,4\% peso/peso de ácido bórico e 1,5\% de sulfato de cobre pentahidratado: Nitromais ${ }^{\circledR}$ ), e o fator D foi composto de diferentes intervalos de entrada de água representados por: $0,3,6,9$ e 12 dias após a aplicação da fonte nitrogenada. A semeadura ocorreu no dia 10/11/2008 sendo utilizada a cultivar IRGA 417, na densidade de $90 \mathrm{~kg} \mathrm{ha}^{-1}$ de sementes. A adubação em linha realizada por ocasião da semeadura, foi de $60 \mathrm{~kg} \mathrm{ha}^{-1} \mathrm{de}_{2} \mathrm{P}_{2} \mathrm{O}_{5}$ $90 \mathrm{~kg} \mathrm{ha}^{-1}$ de $\mathrm{K}_{2} \mathrm{O}$. Para o N foi utilizada a quantidade total de $120 \mathrm{~kg} \mathrm{ha}^{-1}$, dividida em $15 \mathrm{~kg} \mathrm{ha}^{-1} \mathrm{na}$ semeadura, $75 \mathrm{~kg}$ antes da irrigação definitiva (29DAE) e $30 \mathrm{~kg}$ na diferenciação do primórdio floral (65DAE), para ambas as formas, ureia e ureia revestida com $\mathrm{B}$ e $\mathrm{Cu}$. As unidades experimentais mediram 4,0 x 1,87 m $\left(7,48 \mathrm{~m}^{2}\right)$ e a área útil para estimativa da produtividade de grãos foi de 3,0 x 1,19 $\mathrm{m}\left(3,57 \mathrm{~m}^{2}\right)$. Os demais tratos culturais foram realizados conforme recomendação da pesquisa (SOSBAI, 2007).

As avaliações de perdas de $\mathrm{N}$ por volatilização de amônia $\left(\mathrm{NH}_{3}\right)$ foram realizadas com coletores do tipo estático confeccionados a partir de frascos plásticos transparentes tipo PET de dois litros sem a base, com diâmetro de $10 \mathrm{~cm}$, abrangendo $0,008 \mathrm{~m}^{2}$ de área. No interior do frasco foi suspenso, com o auxílio de um arame inoxidável, uma fita de papel filtro com $2,5 \mathrm{~cm}$ de largura e $25 \mathrm{~cm}$ de comprimento umedecida com solução de $\mathrm{H}_{2} \mathrm{SO}_{4} 1 \mathrm{~mol} \mathrm{dm}^{-3}+$ glicerina $2 \%$ $(\mathrm{v} / \mathrm{v})$. A fita permanecia todo o tempo em contato com um recipiente do tipo FALCON contendo $50 \mathrm{ml}$ dessa solução (Araújo et al., 2006). Foram determinadas as quantidades de $\mathrm{N}-\mathrm{NH}_{3}$ retidas nos coletores as 10, 24, 34, 48, 72, 96, 144, 216, 288 horas após a aplicação da fonte nitrogenada no solo. No laboratório, procedeu-se a agitação do frasco contendo a fita e posteriormente retirou-se uma alíquota de $20 \mathrm{ml}$ da solução remanescente que foi destilada e titulada conforme metodologia descrita por Tedesco (1995).

Após 15 dias da aplicação do $\mathrm{N}$ no perfilhamento (44DAE), por ocasião da última aplicação de $\mathrm{N}$ na diferenciação do primórdio floral (65DAE) e no momento da floração plena do arroz (93DAE), realizou-se a avaliação de clorofila e coletou-se $0,0625 \mathrm{~m}^{2}$ de plantas inteiras em cada unidade experimental, para a determinação do teor total de $\mathrm{N}$ na planta, segundo metodologia descrita por Tedesco (1995). Estas foram secas à $70^{\circ} \mathrm{C}$ em estufa de circulação forçada sendo posteriormente moídas. A avaliação de clorofila foi realizada através das leituras SPAD (clorofilômetro SPAD 502), na última folha completamente expandida, em três posições, em três plantas aleatórias por parcela.

Aos 44DAE procedeu-se a coleta de solo, através de trado do tipo calador, retirando uma amostra de $0-10 \mathrm{~cm}$ de profundidade em cada parcela, sendo posteriormente congelada até o momento da determinação do conteúdo das formas minerais de nitrogênio (amônio e nitrato + nitrito) seguindo metodologia descrita por Tedesco (1995).

No início do cultivo foi delimitado um metro de linha de semeadura onde efetuou-se a determinação da estatura no momento da colheita e coletou-se dez panículas para obtenção do número de espiguetas por panícula, da massa de mil grãos e da esterilidade de espiguetas. A produtividade foi determinada colhendo-se manualmente as plantas da área útil das parcelas quando os grãos atingiram grau de umidade média de $20 \%$, as quais foram trilhadas, determinando-se a massa dos grãos e corrigindo-se a umidade para $13 \%$. 
Os dados de temperatura do solo foram coletados a dois centímetros de profundidade sobre solo desnudo e sobre cobertura morta através de geotermômetros, além da temperatura do ar e precipitação diária. Esses dados foram fornecidos pela estação meteorológica do Departamento de Fitotecnia da UFSM, distante cerca de 500 metros da área do experimento. Para todos os parâmetros foram utilizados os valores máximos diários.

As variáveis determinadas foram submetidas à análise de variância, através do teste $\mathrm{F}$, e as médias comparadas pelo teste de Tukey $(\mathrm{P} \leq 0,05)$ para o fator qualitativo enquanto que o fator quantitativo foi analisado através de regressão. Os dados em porcentagem foram transformados para $\mathrm{yt}=\sqrt{\mathrm{y}+1}$.

\section{RESULTADOS E DISCUSSÃO}

Os fluxos de volatilização de $\mathrm{N}-\mathrm{NH}_{3}$ variaram com a fonte de nitrogênio $(\mathrm{N})$ e o sistema de cultivo (Figura 1). No sistema plantio direto (SPD), o início de um fluxo expressivo de perdas de $\mathrm{N}-\mathrm{NH}_{3}$ iniciou a partir de 72 horas, independente da fonte, sendo que a ureia apresentou as maiores perdas atingindo o pico de volatilização às 96 horas, totalizando uma perda acumulada de $47 \%$ do $\mathrm{N}$ aplicado no período de 288 horas. Quando se compara a volatilização com a temperatura do solo com cobertura morta percebe-se que, à medida que havia um acréscimo de temperatura, proporcionalmente havia um aumento no fluxo de perdas de $\mathrm{N}-\mathrm{NH}_{3}$, com maior influência sobre o comportamento do inibidor de urease, uma vez que a ureia manteve as perdas praticamente constantes, pois provavelmente já havia volatilizado boa parte do fertilizante. Soma-se a isso, a precipitação ocorrida no período final da avaliação, a qual potencializou um segundo pico de volatilização do inibidor de urease, demonstrando que esse produto é fortemente influenciado por condições de clima. Quando o solo está inicialmente úmido, ele também está secando continuamente e perdendo $\mathrm{H}_{2} \mathrm{O}$. Isto força a reação de formação da amônia $\mathrm{NH}_{4}+\mathrm{OH}^{-} \Leftrightarrow \mathrm{H}_{2} \mathrm{O}+\mathrm{NH}_{3(\text { gás })}$ para o lado direito da equação, produzindo mais $\mathrm{NH}_{3}$ (Harrell, 2007), o qual é perdido. Além disso, Malhi et al. (2001) sugerem que a umidade do solo favorece a hidrólise de fertilizantes como a ureia porque no processo de evaporação há uma tendência do $\mathrm{N}_{-} \mathrm{NH}_{3}$ chegar até a superfície e ser perdido. O umedecimento do solo, imediatamente após a aplicação das fontes nitrogenadas, é mais importante do que sua condição de umidade no momento da aplicação (Lara Cabezas et al., 1997) e a água somente diminui a volatilização do $\mathrm{N}_{-} \mathrm{NH}_{3}$ se for suficiente para diluir a concentração de oxidrilas $(\mathrm{OH}-)^{3}$ ao redor dos grânulos de ureia. Do contrário, a volatilização é favorecida por estimular a hidrólise do fertilizante.
Mesmo assim, o inibidor de urease apresentou menores perdas de $\mathrm{N}-\mathrm{NH}_{3}$, concentrando seus picos entre 96 e 216 horas após a aplicação e perdas acumuladas de $22 \%$ do total de $\mathrm{N}$ aplicado em cobertura. Esse produto atua inibindo a atividade da enzima urease, pois essa é ativada pelo $\mathrm{Ni}$ (em sua constituição possui 12 átomos de $\mathrm{Ni}$ ) e é inibida por cátions bivalentes entre os quais se destaca o $\mathrm{Cu}$, sendo seu efeito o de inibição competitiva da urease. Já o B muito provavelmente funciona como inibidor não competitivo da urease, 'fixando' o N (Watson, 2000).

Enquanto que no SPD as perdas foram na ordem de $47 \%$ do total aplicado para a fonte ureia, no SPC essas perdas não ultrapassaram 1,2\% e o maior pico de perdas ocorreu às 216 horas. No caso do inibidor de urease, a perda total de $\mathrm{N}_{-} \mathrm{NH}_{3}$ foi de $0,3 \%$ do total de $\mathrm{N}$ aplicado. Através da observação dos dados ambientais, percebe-se que o pico de volatilização das fontes está associado a uma brusca elevação da temperatura nesse sistema de cultivo, a qual ultrapassou os $40^{\circ} \mathrm{C}$, somado á precipitação de $39 \mathrm{~mm}$ ocorrida entre o oitavo e o nono dia de avaliação.

Em termos gerais, a eficiência do inibidor de urease esteve associada basicamente à presença ou à ausência de palhada, visto que a temperatura no solo com cobertura morta é substancialmente menor que a temperatura de um solo desnudo. Quando há resíduo vegetal sobre a superfície do solo, o contato do fertilizante com o solo é diminuído, com isso a palha atua como uma barreira entre o $\mathrm{N}$ do fertilizante e o solo, fazendo com que a $\mathrm{N}-\mathrm{NH}_{3}$, produto da hidrólise, permaneça na superfície dos restos culturais, diminuindo a adsorção aos colóides orgânicos e inorgânicos, e com isso facilitando a volatilização (Cantarella et al., 2008). A atividade da urease que é incentivada na presença de resíduo vegetal está intimamente ligada à presença de matéria orgânica no solo, promovendo a atividade microbiológica e a maior produção da enzima, o que acelera a hidrólise do fertilizante nitrogenado resultando na formação de $\mathrm{N}-\mathrm{NH}_{3}$ (Vargas et al., 2005).

Para as leituras realizadas com o clorofilômetro (Figura 2) houve diferenças significativas no SPD e SPC para o fator intervalo de entrada de água e fontes na primeira avaliação, em que a ureia apresentou o melhor comportamento nos dois sistemas. Isso decorre provavelmente do fato do $\mathrm{Cu}$ reagir com a matéria orgânica formando compostos que não são aproveitáveis de imediato pela planta, ficando indisponível momentaneamente, o que pode prejudicar a formação da molécula de clorofila, pois esse micronutriente tem papel fundamental nesse processo (Taiz \& Zeiger, 2006). Além disso, o Cu apresenta problemas quando misturado com fertilizantes nitrogenados, pois reage para formar compostos que se tornam insolúveis, como os 
fosfatos de amônio. Nas duas avaliações sequenciais, no SPD, não foi verificado o mesmo comportamento, pois as fontes não diferiram entre si, apenas houve diferenças entre os intervalos de entrada de água, em que se observou menores leituras SPAD com o atraso da entrada de água no experimento. Para o SPC, a ureia manteve-se como a melhor fonte até a avaliação realizada aos 93DAE, em que as diferenças não foram mais detectadas.

Avaliando a resposta em teor de $\mathrm{N}$ total na planta (Figura 3), observa-se que houve concordância com os resultados de clorofila, uma vez que na avaliação realizada em laboratório, a resposta foi muito similar à obtida no campo, onde os tratamentos com aplicação de ureia demonstraram maior concentração de $\mathrm{N}$ de uma maneira geral, tendendo a diminuir essa diferença até o estádio da floração plena, nos dois sistemas de cultivo. Isso decorre provavelmente do fato do $\mathrm{Cu}$ reagir com a matéria orgânica formando compostos que não são aproveitáveis de imediato pela planta. Além disso, o $\mathrm{Cu}$ apresenta problemas quando misturado com fertilizantes nitrogenados, pois reage para formar compostos que tornam-se insolúveis, como os fosfatos de amônio, retardando a disponibilidade dos nutrientes a comunidade vegetal.

Em relação ao conteúdo de $\mathrm{N}$ no solo (Figura 4), na avaliação realizada um dia antes da aplicação de $\mathrm{N}$ na iniciação do primórdio floral (65DAE), observa-se que as concentrações de $\mathrm{N}$ na forma de amônio $\left(\mathrm{NH}_{4}^{+}\right)$no solo, nos tratamentos com inibidor de uréase, foram superiores aos tratamentos com ureia. Isso pode ser explicado por dois fatos: a menor volatilização de $\mathrm{N}-\mathrm{NH}_{3}$ ocorrida com o uso dessa fonte, tanto no SPD quanto no SPC, e a menor absorção pela planta, visto que apresentou menor teor de
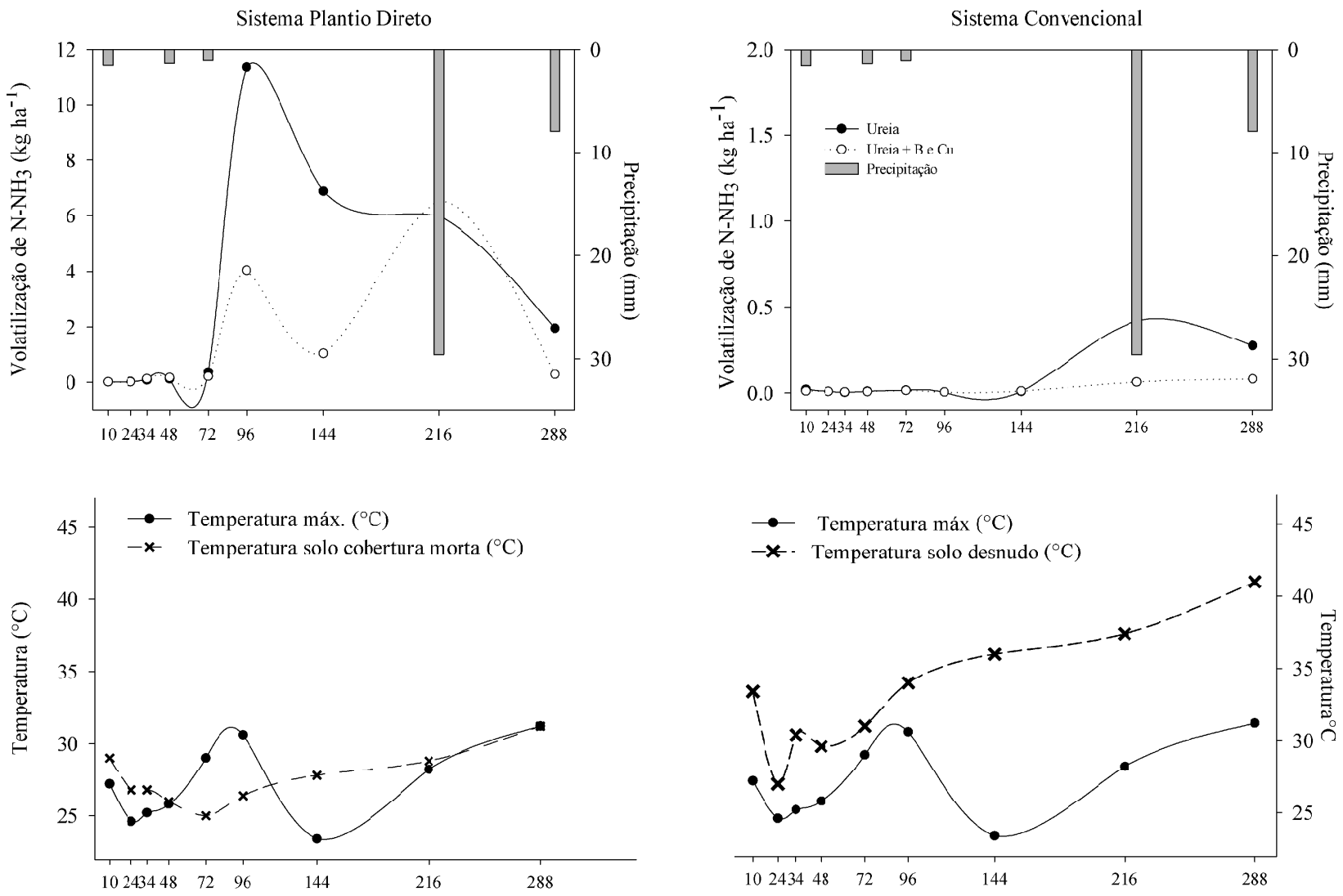

Horas após a aplicação do nitrogênio

Figura 1 - Fluxo de perdas de $\mathrm{N}-\mathrm{NH}_{3}\left(\mathrm{~kg} \mathrm{ha}^{-1}\right)$ em função do fertilizante aplicado, ureia e ureia revestida com B e Cu em dois sistemas de cultivo, plantio direto e convencional, em comparação as condições ambientais (temperatura máxima diária, temperatura do solo desnudo e com cobertura morta a $2 \mathrm{~cm}$ de profundidade e precipitação diária) durante o período de avaliação. Santa Maria, 2010. 
Sistema Plantio Direto
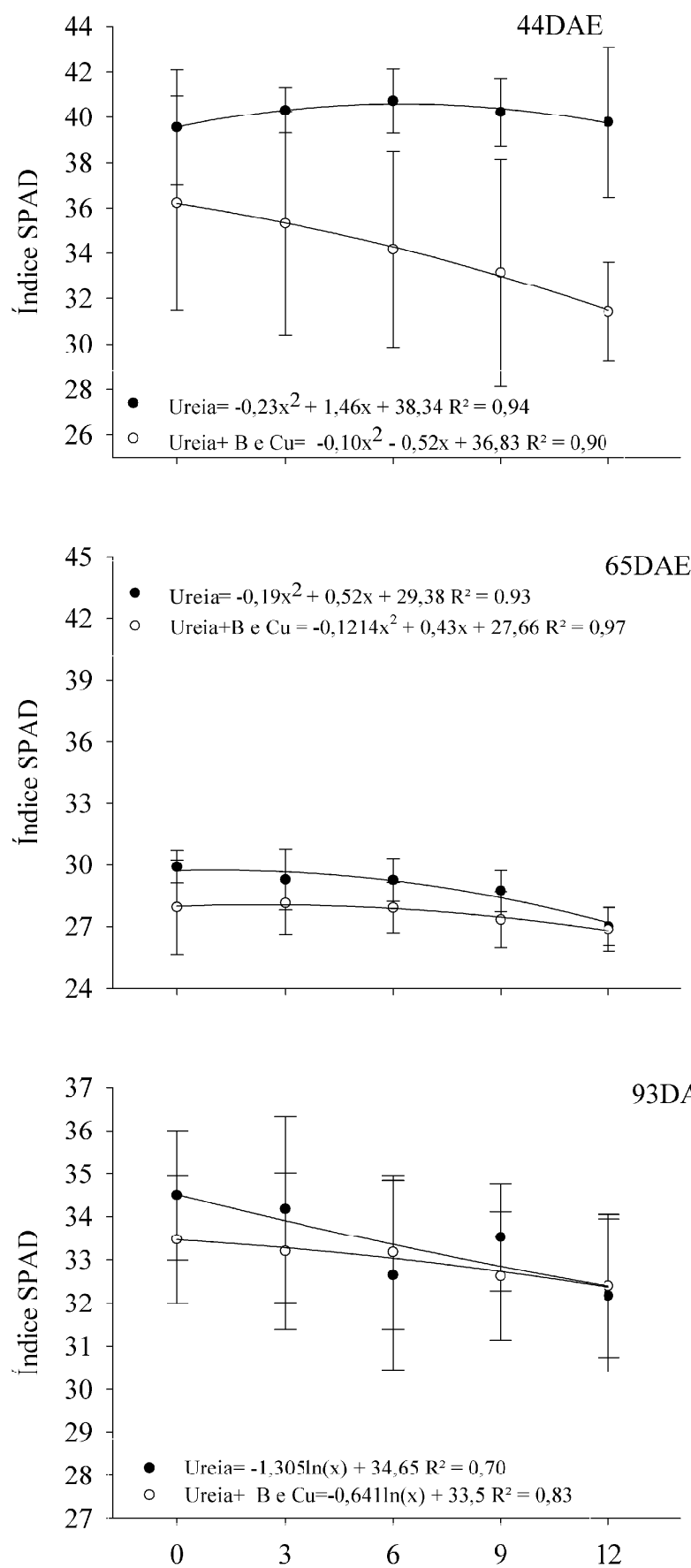

Dias após a aplicação de nitrogênio
Sistema Convencional
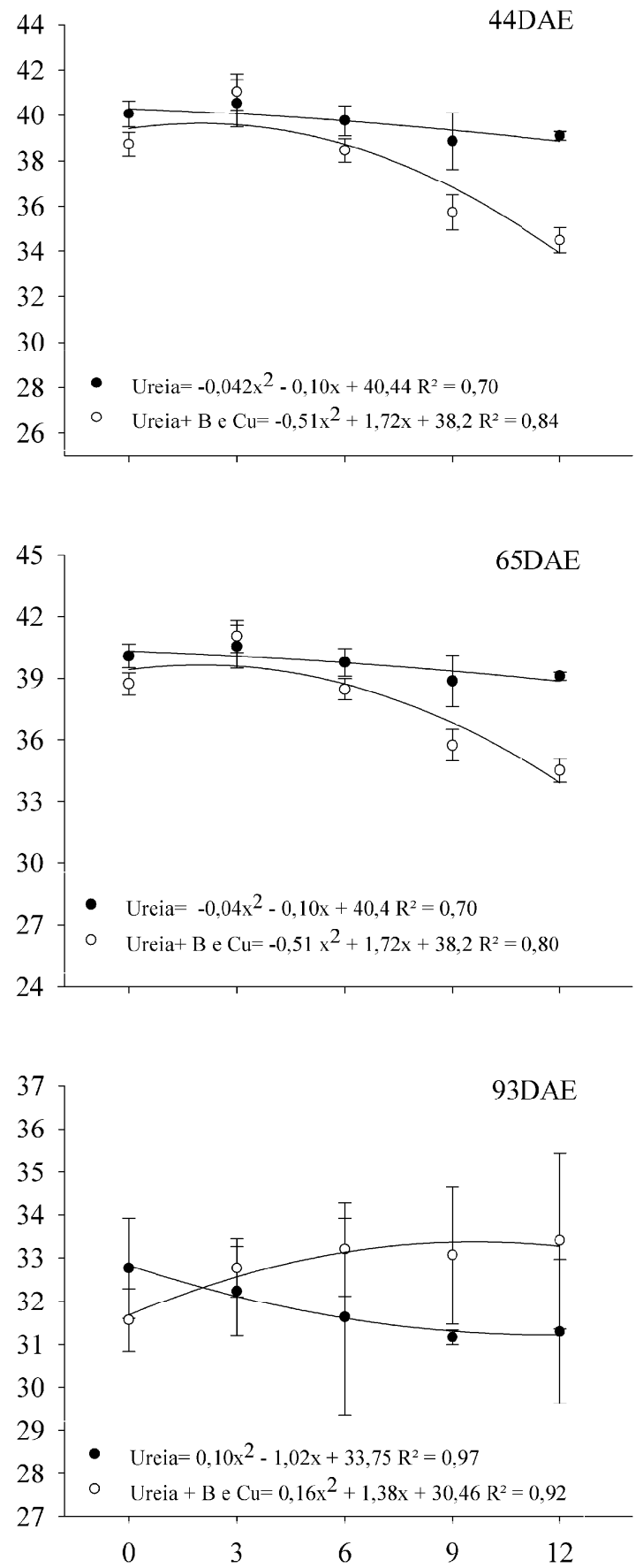

Dias após a aplicação de nitrogênio

Figura 2 - Índice SPAD realizado aos 15 dias após a segunda aplicação de N (44DAE), no momento da diferenciação do primórdio floral (65DAE) e na floração plena (93DAE) na forma de ureia e ureia revestida com $\mathrm{B}$ e $\mathrm{Cu}$ no sistema de cultivo convencional e plantio direto. Santa Maria, 2010.

Ciênc. agrotec., Lavras, v. 35, n. 2, p. 336-345, mar./abr., 2011 
Sistema Plantio Direto
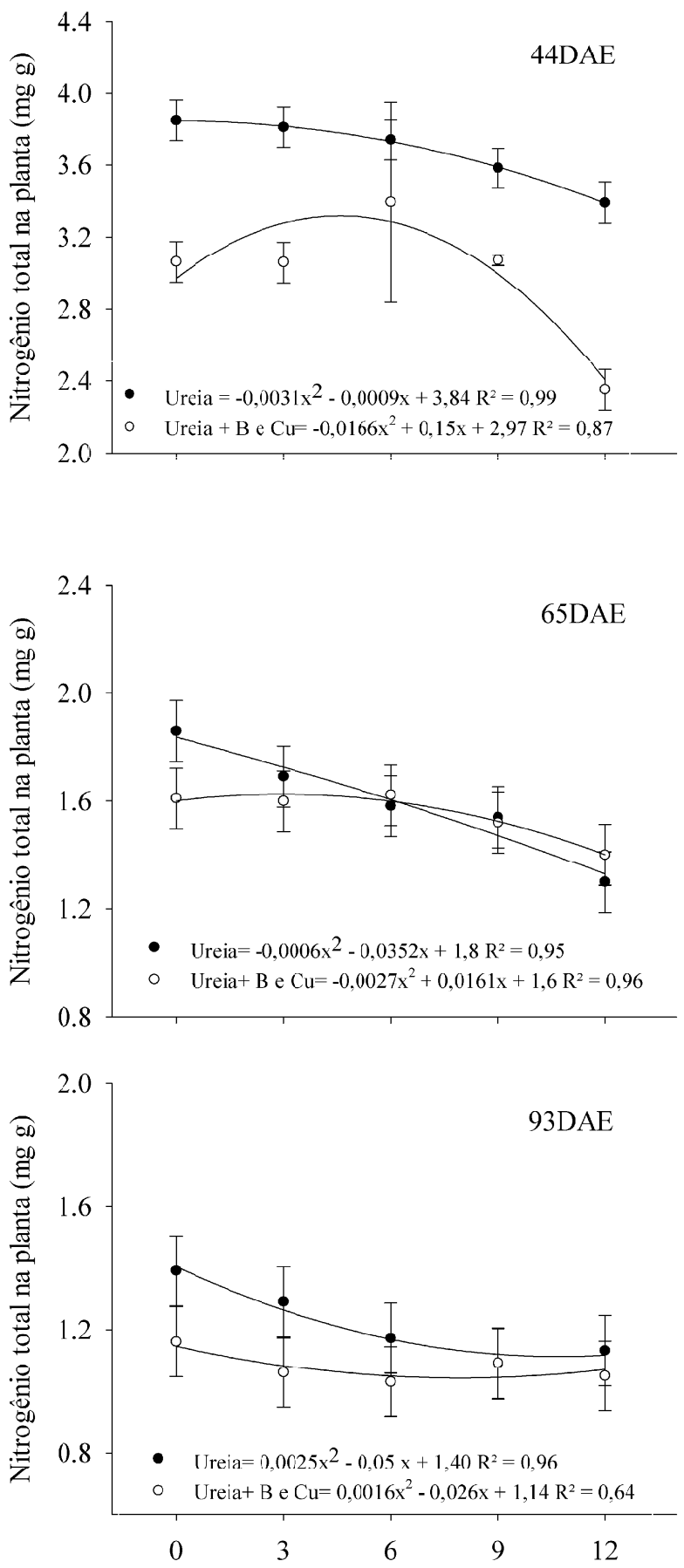

Dias após a aplicação de nitrogênio
Sistema Convencional
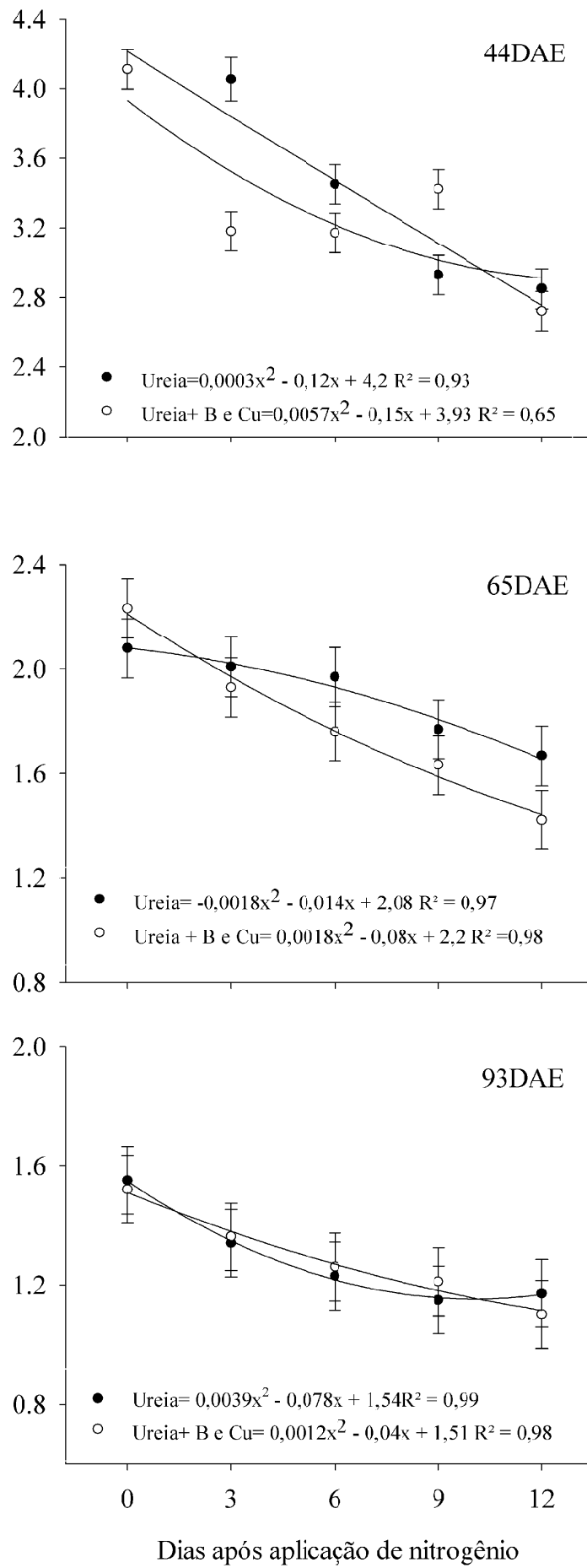

Figura 3 - Teor de nitrogênio (N) na planta em avaliações realizadas 15 dias após a segunda aplicação de N (44DAE), no momento da diferenciação do primórdio floral (65DAE) e na floração plena (93DAE) na forma de ureia e ureia revestida com B e Cu no sistema de cultivo convencional e plantio direto. Santa Maria, 2010.

Ciênc. agrotec., Lavras, v. 35, n. 2, p. 336-345, mar./abr., 2011 
$\mathrm{N}$ na planta em comparação a ureia, reforçando o fato de que o $\mathrm{Cu}$ pode estar associado/reagindo com elementos do solo, o que regula sua liberação gradual às plantas ao longo do período de cultivo do arroz. Segundo Zaman et al. (2008) a retenção do fertilizante na forma de $\mathrm{N}-\mathrm{NH}_{4}{ }^{+}$no solo pode melhorar o crescimento das plantas, pois é requerido menos energia para converter $\mathrm{N}-\mathrm{NH}_{4}{ }^{+}$em aminoácidos comparado ao nitrato $\left(\mathrm{N}-\mathrm{NO}_{3}{ }^{-}+\mathrm{NO}_{2}\right)$.

De uma maneira geral, $\mathrm{o} N-\mathrm{NH}_{4}^{+}$tendeu a diminuir seu conteúdo no solo à medida que era atrasada a entrada de água no experimento ocorrendo paralelamente à elevação do conteúdo de $\mathrm{N}-\mathrm{NO}_{3}{ }^{-}+\mathrm{NO}_{2}$, pois os fertilizantes amoniacais quando aplicados no solo, tendem a chegar a forma de $\mathrm{N}_{-} \mathrm{NO}_{3}{ }^{-}+\mathrm{NO}_{2}$ pelo processo de nitrificação, dependendo da disponibilidade de oxigênio para que ocorra essa transformação (Schulten \& Schnitzer, 1998). A ureia

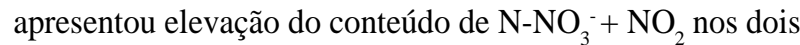
sistemas, pois apresentou menor concentração de $\mathrm{N}-\mathrm{NH}_{4}^{+}$, que é substrato para a nitrificação, em detrimento a

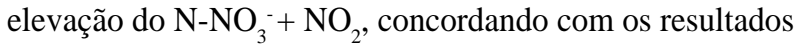
de Zaman et al. (2008).

Apesar de diminuir as perdas por volatilização de N$\mathrm{NH}_{3}$, os benefícios do inibidor de urease não foram convertidos em maior produtividade, pois nenhum dos componentes do rendimento (número de panículas, grãos por panícula, massa de mil grãos e esterilidade de espiguetas) e estatura diferiram estatisticamente da ureia, inclusive produtividade de grãos (Tabela 1) concordando com os resultados obtidos por Hernandes et al. (2010). As diferenças foram detectadas apenas para os intervalos de entrada de água, no SPD. Isso reforça o argumento de que a entrada de água deve ser o mais cedo possível no ciclo de vida da planta para que o arroz possa expressar seu máximo potencial produtivo (Mariot et al., 2009). Segundo Cantarella (2007) o grande impasse da utilização desses produtos é o fato de que apesar de serem eficientes na redução da volatilização de $\mathrm{N}-\mathrm{NH}_{3}$ ao manterem o $\mathrm{N}$ em uma forma mais estável no solo, não expressam esse resultado em ganhos de produtividade, o que não os torna vantajosos em termos econômicos.
Sistema Plantio Direto
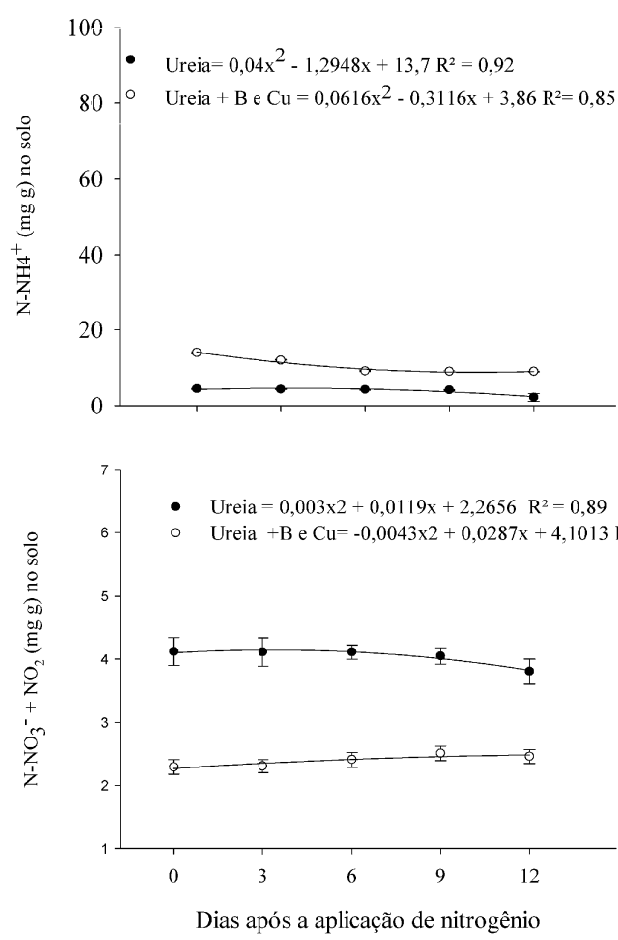

Sistema Convencional
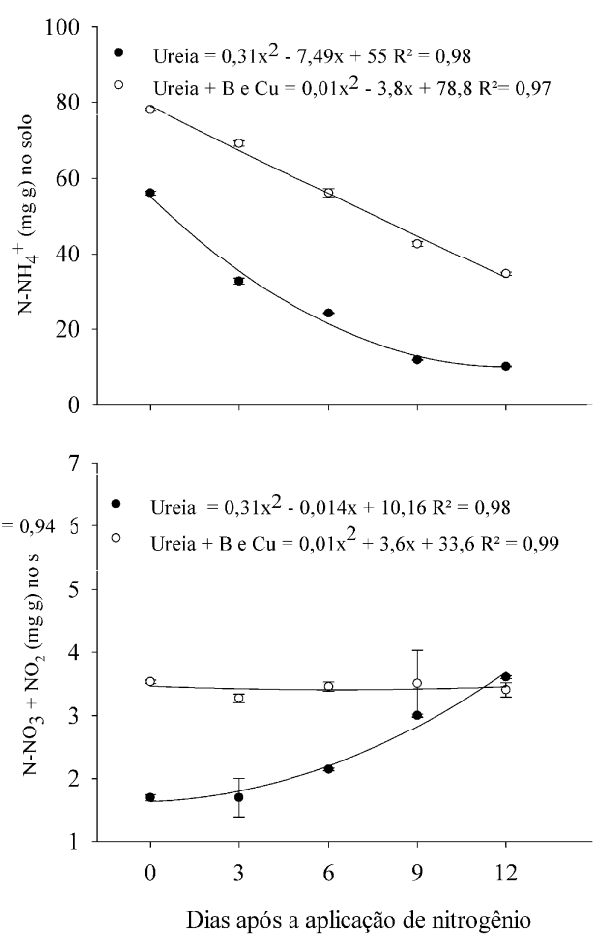

Figura 4 - Conteúdo de nitrogênio $(\mathrm{N})$ no solo na forma de amônio $\left(\mathrm{NH}_{4}\right)$ e nitrato + nitrito $\left(\mathrm{NO}_{3}+\mathrm{NO}_{2}\right)$ em avaliação realizada 15 dias após a segunda aplicação de $\mathrm{N}$ (44DAE) na forma de ureia e ureia revestida com $\mathrm{B}$ e Cu no sistema de cultivo convencional e plantio direto. Santa Maria, 2010. 


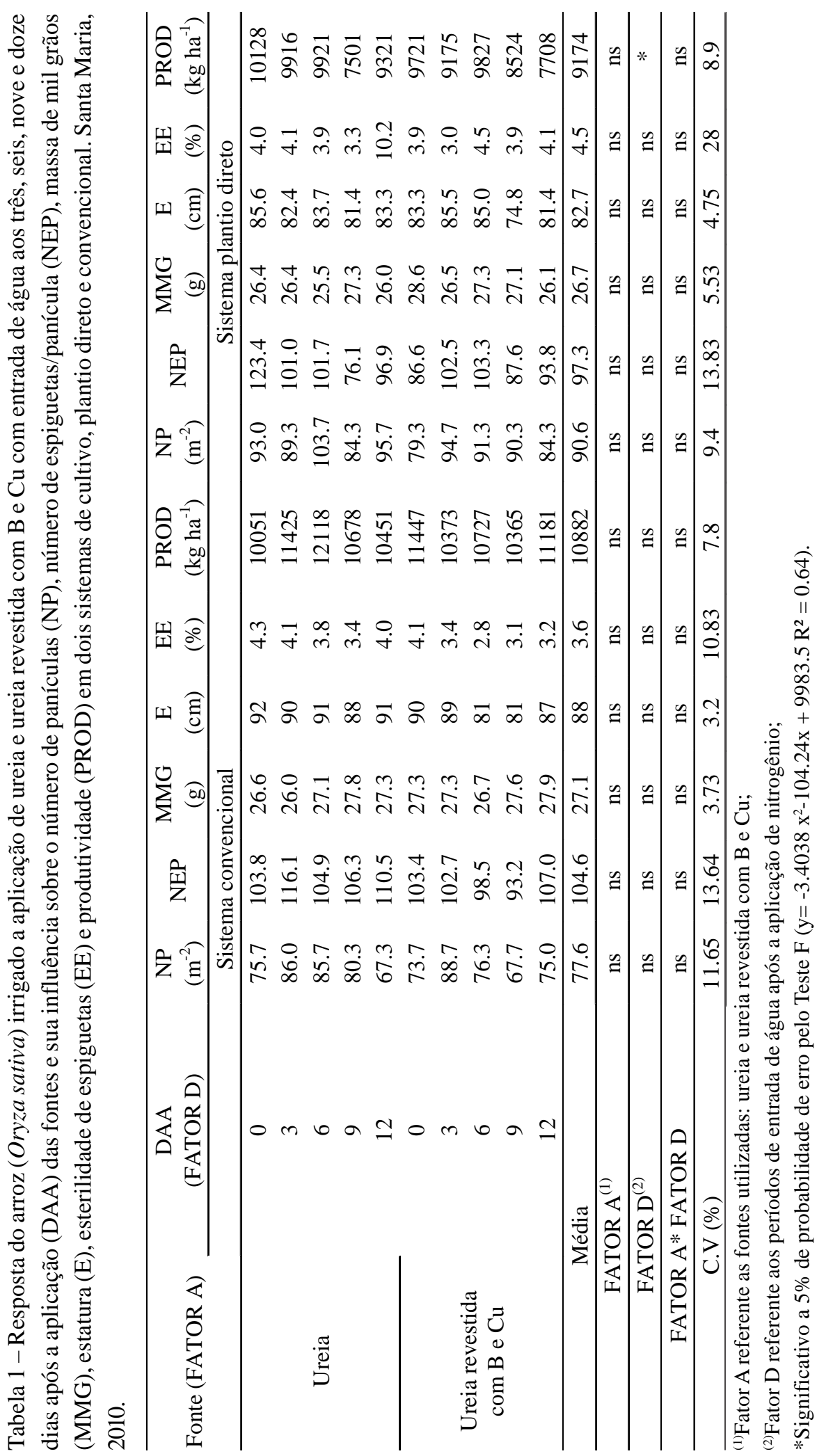

Ciênc. agrotec., Lavras, v. 35, n. 2, p. 336-345, mar./abr., 2011 


\section{CONCLUSÕES}

A utilização da ureia revestida com $\mathrm{B}$ e Cu retarda e reduz as perdas de $\mathrm{N}$ por volatilização de amônia em comparação com a ureia, estando sua eficiência associada às condições do solo e do clima, influenciadas pelo sistema de cultivo do arroz, o que nem sempre se expressa em produtividade.

Nos sistemas plantio direto e convencional, o melhor desempenho do inibidor de urease em relação a diminuição da volatilização ocorre à medida em que se retarda o estabelecimento da lâmina de água de irrigação após aplicação do fertilizante. Quando o intervalo entre a aplicação de nitrogênio e a irrigação for dentro do recomendado (três dias), não há vantagem da adição do produto em relação ao uso isolado da ureia, pois o pico de volatilização da ureia ocorre a partir de 72 horas após a aplicação do fertilizante.

\section{AGRADECIMENTOS}

À Fundação de Apoio à Pesquisa do Estado do Rio Grande do Sul (FAPERGS) pela bolsa de Iniciação Científica do Rio Grande do Sul a Mara Grohs, ao Conselho Nacional de Desenvolvimento Científico e Tecnológico pela bolsa de Produtividade em Pesquisa a Enio Marchesan e de Iniciação científica a Rafael Bruck Ferreira e de apoio técnico a Gerson Meneghetti Sarzi Sartori.

\section{REFERÊNCIAS BIBLIOGRÁFICAS}

ARAÚJO, E. da S.; BODDEY, M.R.; URQUIAGA, S.; ALVES, B.J.R. Câmara coletora para quantificação do N$\mathbf{N H}_{3}$ volatilizado do solo. Seropédica: Embrapa Agrobiologia, 2006. 4p. (Embrapa Agrobiologia. Comunicado técnico, 87). Disponível em: 〈http://www. cnpab.embrapa.br/publicacoes/download/cot087.pdf $>$. Acesso em: 25 fev. 2010.

CANTARELLA, H. Nitrogênio. In: NOVAIS, R.F.; ALVAREZ, V.H.; BARROS, N.F.; FONTES, R.L.F.; CANTARUTTI, R.B.; NEVES, J.C.L. (Eds.). Fertilidade dos solos. Viçosa, MG: SBCS/UFV, 2007. p.376-470.

CANTARELLA, H.; TRIVELIN, P.C.O.; CONTIN, T.L.M.; DIAS, F.L.F.; ROSSETTO, R.; MARCELINO, R.; COIMBRA, R.B.; QUAGGIO, J.A. Ammonia volatilisation from urease inhibitor-treated urea applied to sugarcane trash blankets. Scientia Agricola, Piracicaba, v.65, p.97-401, 2008.
DUARTE, F.M.; POCOJESKI, E.; SILVA, L.S. da; GRAUPE, F.A.; BRITZKE, D. Perdas de nitrogênio por volatilização de amônia com aplicação de ureia em solo de várzea com diferentes níveis de umidade. Ciência Rural, Santa Maria, v.37, n.3, p.705-711, 2007.

\section{EMPRESA BRASILEIRA DE PESQUISA}

AGROPECUÁRIA. Centro Nacional de Pesquisa de Solos. Sistema brasileiro de classificação dos solos. Brasília: Embrapa-SPI, 2006. 306p.

HARRELL, D. Timing is everything with nitrogen fertilizer applications. Rice Research Station News, v.4, n.2, 2007.

HERNANDES, A; BUZETTI, S; ANDREOTTI, M; ARF, O; SÁ, M.E. de. Doses, fontes e épocas de aplicação de nitrogênio em cultivares de arroz. Ciência e Agrotecnologia, Lavras, v.34, n.2, p.307-312, mar./abr., 2010.

KISS, S.; SIMIHAIAN, M. Improving efficiency of urea fertilizers by inhibition of soil urease activity. Norwell: Kluwer Academic, 2002. 341p.

LARA CABEZAS, W.A.R.; KORNDÖRFER, G.H.; MOTTA, S.A. Volatilização de $\mathrm{N}_{-} \mathrm{NH}_{3}$ na cultura de milho: I., efeito da irrigação e substituição parcial da ureia por sulfato de amônio. Revista Brasileira de Ciência do Solo, Viçosa, v.21, p.481-487, 1997.

MALHI, S.S.; GRANT, C.A.; JOHNSTON, A.M.; GILL, K.S. Nitrogen fertilization management for no-till cereal production in the Canadian great plains: a review. Soil \& Tillage Research, Amsterdam, v.60, n.3/4, p.101122, 2001.

MARIOT, C.H.P.; VIEIRA, V.M.; SILVA, P.R.F. da; MENEZES, V.G.; OLIVEIRA, C.F. de; FREITAS, T.F.S. de Práticas de manejo integradas para produção de arroz irrigado. Pesquisa Agropecuária Brasileira, Brasília, v.44, n.3, p.243-250, 2009.

SCHULTEN, H.R.; SCHNITZER, M. The chemistry of soil organic nitrogen: a review. Biology Fertility Soils, Berlin, v.26, p.1-15, 1998.

SCIVITTARO, W.B.; GOMES, A.S.; ROSSI, F. de; NUNES, D.R. Uso do inibidor de urease NBPT na cultura de arroz irrigado. Pelotas: Embrapa Clima Temperado, 2005. Disponível em: <http://WwW.cnpaf. embrapa.br/publicacao/seriedocumentos $>$. Acesso em: 20 abr. 2010. 
SCIVITTARO, W.B.; MACHADO, M.O. Adubação e calagem para a cultura do arroz irrigado. In: GOMES, A. da S.; MAGALHÃES JÚNIOR, A.M. de (Eds.). Arroz irrigado no Sul do Brasil. Pelotas: Embrapa Clima Temperado; Brasília: Embrapa Informação Tecnológica, 2004. p.259-303.

SOCIEDADE SUL-BRASILEIRA DEARROZ IRRIGADO. Arroz irrigado: recomendações técnicas da pesquisa para o Sul do Brasil. Santa Maria, 2007. 159p.

TAIZ, L.; ZEIGER, E. Fisiologia vegetal. 3.ed. Porto Alegre: Artmed, 2006. 722p.

TEDESCO, M.J. Análise de solo, plantas e outros materiais. Porto alegre: UFRGS, 1995. 174p.
VARGAS, L.K.; SELBACH, P.A.; SÁ, E.L.S.

Imobilização de nitrogênio em solo cultivado com milho em sucessão à aveia preta nos sistemas plantio direto e convencional. Ciência Rural, Santa Maria, v.35, n.1, p.76-83, 2005.

WATSON, C.J. Urease activity and inhibition: principles and practice. London: The International Fertiliser Society, 2000. 40p.

ZAMAN, M.; NGUYEN, M.L.; BLENNERHASSETT, J.D.; QUIN, B.F. Reducing $\mathrm{NH}_{3}, \mathrm{~N}_{2} \mathrm{O}$ and $\mathrm{NO}_{3}$ losses from a pasture soil with urease or nitrification inhibitors and elemental S-amended nitrogenous fertilizers. Biology Fertility Soils, Berlin, v.44, n.5, p.693-705, 2008. 